\title{
Cloning and characterization of cDNAs encoding steroidogenic acute regulatory protein from freshwater stingrays (Potamotrygon spp.)
}

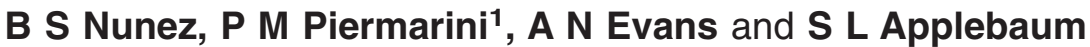 \\ The University of Texas Marine Science Institute, 750 Channel View Drive, Port Aransas, Texas 78373, USA \\ ${ }^{1}$ Yale University School of Medicine, Department of Cellular and Molecular Physiology, New Haven, Connecticut, USA \\ (Requests for offprints should be addressed to B S Nunez; Email: nunez@utmsi.utexas.edu)
}

\begin{abstract}
The steroidogenic acute regulatory protein (StAR) is critical to the regulated synthesis of steroids in vertebrates. We have isolated cDNA sequences encoding StAR in the freshwater stingrays Potamotrygon hystrix and $P$. motoro. A single $P$. hystrix StAR transcript (3376 bp) and two overlapping $P$. motoro StAR transcripts (1272 and $3365 \mathrm{bp}$ ) were isolated. The $P$. hystrix and $P$. motoro StAR transcripts contain open reading frames encoding proteins of 284 amino acids that are $99 \%$ identical to each other and 56-64\% identical to other StAR proteins. Pregnenolone synthesis by green monkey kidney (COS-1) cells transfected with an expression construct encoding a human cholesterol side chain cleavage/adrenodoxin reductase/adrenodoxin fusion protein was increased 16 -fold by coexpression with a pCMV5/P. motoro StAR expression construct. Northern blot analysis revealed a single $4000 \mathrm{bp}$ StAR transcript in the $P$. motoro interrenal gland, but RT-PCR indicates StAR mRNA is also expressed in the brain, gonads, atria, ventricle, gill (female only) and muscle (female only). Expression in extragonadal and extraadrenocortical tissues is an indication that StAR may be critical to processes other than steroidogenesis. The longest $P$. motoro StAR transcript contains a sequence with great similarity to short interspersed repetitive elements found in other elasmobranchs. This study is the first to isolate and characterize elasmobranch StAR cDNA sequences and to demonstrate the activity of a nonmammalian StAR protein in a heterologous expression system.
\end{abstract}

Journal of Molecular Endocrinology (2005) 35, 557-569

\section{Introduction}

Steroid hormones cannot be stored intracellularly and must be synthesized on demand. The single most important factor regulating the timing and rate of steroidogenesis appears to be the steroidogenic acute regulatory protein (StAR) (for review see Stocco 2001). StAR belongs to a family of proteins that share a cholesterol-binding motif termed the StAR-related lipid transfer (START) domain; this domain accommodates cholesterol and/or cholesterol-like sterols (Strauss et al. 2003). The START family is diverse, including StAR-like MLN-64 proteins and phosphatidylcholine transfer proteins from animals and Glabra2 homeobox proteins from plants, among other proteins (Strauss et al. 2003).

StAR proteins facilitate the transfer of cholesterol, the precursor of all steroids, from the outer mitochondrial membrane to the inner mitochondrial membrane, where cholesterol is converted into pregnenolone by cytochrome P450 cholesterol side chain cleavage enzyme (SCG) (reviewed by Stocco 2001). As the synthesis of a diverse group of steroids, each having distinctive physiological effects, depends on the conversion of cholesterol to pregnenolone, StAR-mediated steroidogenesis plays an important role in several biological processes. For example, the timely synthesis of steroids is crucial for successful reproduction (e.g. sex steroid synthesis), maintaining ionic homeostasis (e.g. mineralocorticoid synthesis) and for responding to stress (e.g. glucocorticoid synthesis).

Identification of the factors that regulate steroidogenesis can help define the physiological role of specific steroids, because steroids cannot be sequestered and therefore must be made when needed. For example, adrenocorticotropic hormone (ACTH) is released by the pituitary in response to stress and induces glucocorticoid synthesis. Similarly, angiotensin II (AII) is involved in the regulation of salt and water balance and mediates its actions in part by inducing the synthesis of mineralocorticoids. In mammals, factors such as ACTH and AII are known to induce steroidogenesis through a process that is sensitive to inhibitors of translation (e.g. cycloheximide), but insensitive to inhibitors of transcription (e.g. actinomycin D) (Ferguson 1962, 1963, Garren et al. 1965, 1966). Recent work indicates that the 
cycloheximide-sensitive induction of steroidogenesis is dependent on the rapid translation of StAR mRNA (for review see Stocco 2001).

In fishes, a single steroid is thought to serve as both a mineralocorticoid and a glucocorticoid, but the precise role of corticosteroids in these animals is poorly defined. Characterization of the structure and regulation of StAR from fishes will greatly enhance our understanding of the role of steroidogenesis in maintaining homeostasis in these animals. The sequences of cDNA clones encoding teleost forms of StAR have recently been determined and studies of StAR regulation in gonadal and adrenocortical tissues of teleosts have been conducted (Bauer et al. 2000, Kusakabe et al. 2002b, von Hofsten et al. 2002, Li et al. 2003, Geslin \& Auperin 2004). However, the nature of the teleost head kidney, a tissue composed of adrenocortical as well as several other cell types, complicates the study of steroidogenesis in these fishes. The elasmobranch interrenal gland is a good model tissue to study StAR in fishes as it is a discrete, encapsulated gland composed of a single cell type whose sole function is to produce the

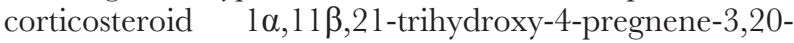
dione ( $1 \alpha$-hydroxycorticosterone; $1 \alpha$-B) (Idler \& Truscott 1966, Idler et al. 1967).

To date, no study has directly examined the regulation and role of StAR in elasmobranch steroidogenesis. Previous work has shown that (i) the rate of interrenal gland steroidogenesis in marine elasmobranchs is increased by ACTH (Klesch \& Sage 1973, Hazon \& Henderson 1985, Armour et al. 1993, Nunez \& Trant 1999); (ii) the induction of steroidogenesis by ACTH in the Atlantic stingray, Dasyatis sabina is sensitive to cycloheximide, but not actinomycin D (Nunez \& Trant 1999); and (iii) AII induces $1 \alpha-B$ synthesis in the interrenal glands of the narrowly euryhaline European lesser spotted dogfish (Scyliorhinus canicula) (Hazon \& Henderson 1985, Armour et al. 1993, Anderson et al. 2001), but not in the fully euryhaline $D$. sabina (Nunez \& Trant 1999). These investigations indicate that the regulation of adrenocortical steroidogenesis may differ between elasmobranch species with different salinity tolerances. Therefore, in order to define the homeostatic role of corticosteroids in elasmobranchs, it will be necessary to examine the regulation of interrenal gland steroidogenesis in stenohaline and euryhaline species.

Stingrays of the family Potamotrygonidae are stenohaline freshwater elasmobranchs that cannot survive in seawater because of their inability to retain nitrogenous osmolytes (i.e. urea and trimethylamine oxide) and reduced size of their salt-secreting rectal gland compared with marine elasmobranchs (Thorson et al. 1967, 1978, Thorson 1970, Gerst \& Thorson 1977). Because they obviously face very different ionoregulatory problems than marine elasmobranchs, Potamotrygonid rays are excellent comparative models relative to euryhaline species such as D. sabina. Indeed, there is a growing body of literature regarding ionoregulation in these animals (for example, see Thorson 1970, Carrier \& Evans 1973, Gerst \& Thorson 1977, Wood et al. 2002, 2003). The goals of the current investigation were to isolate and characterize cDNA clones encoding StAR from the interrenal glands of freshwater stingrays (Potamotrygon hystrix and $P$. motoro) because of the importance of StAR to the regulated synthesis of corticosteriods that are involved in elasmobranch ionoregulation and other homeostatic processes (e.g. the stress response).

\section{Materials and methods}

\section{Animals}

Initial studies were conducted using tissues collected from $P$. hystrix, which were purchased from International Fisheries (Miami, FL, USA) and held in accordance to guidelines established by the University of Florida's Institutional Animal Care and Use Committee. When it became difficult to obtain verified specimens of $P$. hystrix from commercial sources, $P$. motoro (a closely related species) were purchased from The Aquarium of the Americas (New Orleans, LA, USA). The Aquarium of the Americas has maintained a breeding colony of captive $P$. motoro for 13 years and employs experts in the husbandry and biology of freshwater stingrays. Upon arrival at the University of Texas Marine Science Institute, the animals were anesthetized in $0.05 \%$ MS-222 and pithed by spinal transection.

\section{Isolation of freshwater stingray StAR cDNA sequences}

Tissues were excised immediately from the pithed stingrays, then frozen in liquid nitrogen and stored at $-80{ }^{\circ} \mathrm{C}$ until use. Total RNA was isolated with Tri-Reagent (Sigma) following the manufacturer's instructions and used as template for reverse transcription (RT) (Clontech). In standard RT reactions, total RNA $(1 \mu \mathrm{g})$ mixed with $100 \mathrm{ng}$ random hexamer primers $\left(10 \mu\right.$ l total volume) was heated at $70{ }^{\circ} \mathrm{C}$ for $10 \mathrm{~min}$ and then chilled on ice for $2 \mathrm{~min}$. First-strand reaction buffer $(1 \times$ final concentration), dithiothreitol $(10 \mathrm{mM}$ final concentration), dNTPs $(1 \mathrm{mM}$ final concentration), RNase inhibitor (40 units; Invitrogen) and Powerscript reverse transcriptase $(1 \mu$ l enzyme mix; Clontech) were added and the reactions incubated for 10 min at $25^{\circ} \mathrm{C}$. Reactions were then incubated at $42{ }^{\circ} \mathrm{C}$ for $1 \mathrm{~h}$ and terminated by heating at $70^{\circ} \mathrm{C}$ for $10 \mathrm{~min}$. RT reactions were subsequently diluted 1:10 with DNase-free water and used as template for the PCR.

$P$. hystrix interrenal gland RNA was initially used as template for RT-PCR to obtain cDNA clones encoding freshwater stingray StAR. One-tenth of a $P$. hystrix 
interrenal gland RT reaction was added to a total volume of $25 \mu \mathrm{l}$ containing $1 \times$ Advantage 2 reaction buffer (Clontech), $1 \mathrm{mM}$ dNTPs, 20 pmol each sense (5'-GCATGGARGGNATGGGNGAGTGGAA-3') and antisense (5'-TYTTNGGGAGGCANGGYTTSAG GTC-3') primers (as described in Bauer et al. 2000) and $0.5 \mu \mathrm{l}$ Advantage 2 Polymerase mix (Clontech). PGR thermal parameters were: $95^{\circ} \mathrm{C}$ for 2 min followed by 35 cycles of $30 \mathrm{~s}$ at $95^{\circ} \mathrm{C}, 30 \mathrm{~s}$ at $45^{\circ} \mathrm{C}$ and $30 \mathrm{~s}$ at $72{ }^{\circ} \mathrm{C}$. Products of this reaction were resolved on a $2 \%$ agarose gel in Tris-borate $(90 \mathrm{mM})$, EDTA $(2 \mathrm{mM})$ buffer (TBE) and visualized with ethidium bromide. Amplicons of the appropriate size were ligated into the pCRII vector (Invitrogen) and used to transform competent Escherichia coli (Top 10; Invitrogen). Plasmid DNA was isolated from bacteria using a commercial plasmid isolation procedure (Sigma) and sequenced to determine the identity of inserted DNA.

Rapid amplification of cDNA ends (RACE) was used to isolate the 5'- and 3'-ends of freshwater stingray StAR mRNAs. RACE-ready cDNA libraries were synthesized using $P$. hystrix interrenal gland total RNA and a commercial kit (SMART RACE; Clontech), following the manufacturer's protocol. Both 5'-RACE and 3'-RACE first-strand reactions were diluted 1:10 with Tricine-EDTA $(10 \mathrm{mM}$ and $1 \mathrm{mM}$ respectively). To obtain the 3 '-end of $P$. hystrix StAR transcripts, one-tenth of the 3'-RACE first-strand reaction was added to a total volume of $25 \mu \mathrm{l}$ containing $1 \times$ Advantage 2 reaction buffer, $1 \mathrm{mM}$ dNTPs, 20 pmol $P$. hystrix StAR-specific sense primer (5'-CTGGAGAAACTGGGGGCAATGT GATCAG-3'), $2 \cdot 5 \mu \mathrm{l} \quad 10 \times$ SMART RACE universal primer mix and $0.5 \mu \mathrm{l}$ Advantage 2 polymerase mix. The Advantage 2 polymerase mix contains a small amount of proofreading polymerase and has three times the fidelity of standard thermostable polymerase mixes. The $5^{\prime}$-end of the P. hystrix StAR transcript was obtained in a similar manner except one-tenth of the $5^{\prime}$-RACE first-strand reaction was used as template and 20 pmol $P$. hystrix StAR-specific antisense primer (5'-GGCCAT CGCTGCTAGGAAGCAAGTTGAG-3') were used as the gene-specific primer. Thermal parameters for RACE touchdown PCR were: $95^{\circ} \mathrm{C}$ for $2 \mathrm{~min}$; five cycles of $95{ }^{\circ} \mathrm{C}$ for $5 \mathrm{~s}$ and $72{ }^{\circ} \mathrm{C}$ for $180 \mathrm{~s}$; five cycles of $95^{\circ} \mathrm{C}$ for $5 \mathrm{~s}, 70{ }^{\circ} \mathrm{C}$ for $10 \mathrm{~s}$ and $72{ }^{\circ} \mathrm{C}$ for $180 \mathrm{~s} ; 25$ cycles of $95^{\circ} \mathrm{C}$ for $5 \mathrm{~s}, 68^{\circ} \mathrm{C}$ for $10 \mathrm{~s}$ and $72{ }^{\circ} \mathrm{C}$ for $180 \mathrm{~s}$. Products of these reactions were resolved on a $1 \%$ agarose gel in TBE and visualized with ethidium bromide. PCR products were ligated into the pCR II cloning vector (Invitrogen) and sequenced. To obtain StAR sequence from $P$. motoro, we synthesized RACE-ready cDNA libraries from $P$. motoro interrenal gland total RNA as described above. P. hystrix and P. motoro StAR primers were then used in standard RT-PGR, 5'-RAGE and $3^{\prime}$-RACE reactions to obtain $P$. motoro StAR sequence. To obtain accurate consensus sequences of the $P$. hystrix and $P$. motoro StAR mRNAs, at least three different 5'-RACE and 3 '-RACE clones were sequenced in both directions. The open reading frames encoding $P$. hystrix and $P$. motoro StAR were sequenced at least three times more in both directions during the creation of expression constructs.

\section{Sequence alignments and molecular phylogenetic analysis}

To determine their relationship to other members of the START family, the deduced amino acid sequences of the putative $P$. hystrix and $P$. motoro StAR proteins were included in molecular phylogenetic analysis with the sequences of Salvelinus fontinalis (brook trout; accession AAG39689), Oncorhynchus mykiss (rainbow trout; accession BAB18779), Anguilla japonica (Japanese eel; accession BAC66210), Danio rerio (zebrafish; accession AAH75967), Gadus morhua (Atlantic cod; accession AY291434·1), Xenopus laevis (African clawed frog; accession Q9DG08), Gallus gallus (chicken; accession Q9DG09), Taeniopygia guttata (zebrafinch; accession AY505123·1), Mus musculus (mouse; accession P51557), Mesocricetus auratus (hamster; accession P70114), Rattus norvegicus (rat; accession P97826), Equus caballus (horse; accession O46689), Sus scrofa (pig; accession Q28996), Ovis aries (sheep; accession P79245), Bos tarus (cow; accession Q28918) and Homo sapiens (human; accession P49675) StAR proteins, Caenorhabditis elegans (accession NP_498027), zebrafish (accession AAG28603; partial amino acid sequence), Xenopus tropicalis (accession AAH76666), mouse (accession BC003313) and human (accession CAA56489) MLN64, mouse (accession Q99JV5) and human (accession Q96DR4) START-domain-containing 4 protein (STARD4), mouse (accession Q9 EPQ7) and human (accession Q9 NSY2) STARD5, mouse (accession P59096) and human (accession P59095) STARD6, mouse (accession Q9 JMD3) and human (accession Q9Y365) STARD10, mouse (accession Q923Q2) and human (accession Q9Y3 M8) STARD13, and the $C$. elegans F25H2.6 (accession CAB02094) putative START protein using the Clustal W algorithm (Thompson et al. 1994). Molecular phylogenetic analysis was then performed using the Neighbor Joining method (Saitou \& Nei 1987) in MEGA version 3 (Kumar et al. 2004). The analysis parameters for the alignment were: pairwise alignment gap opening penalty $=10$; pairwise alignment gap extension penalty $=0 \cdot 1$; multiple alignment gap opening penalty $=10$; multiple alignment gap extension penalty $=0 \cdot 2$; using a Gonnet protein weight matrix with residue-specific and hydrophobic penalties and gap separation distance of 4 . Two thousand iterations were used to generate a bootstrap consensus tree, which was rooted with the C. elegans $\mathrm{F} 25 \mathrm{H} 2 \cdot 6$ putative START protein.

To determine if amino acid residues and structural motifs important to StAR structure and function are 
conserved in the deduced amino acid sequences encoded by the putative $P$. motoro StAR cDNA, this sequence was aligned with STAR proteins from the Japanese eel, rainbow trout, African clawed frog, chicken and human using the Clustal W algorithm (Thompson et al. 1994) in the Vector NTI software package (Invitrogen). Computer analysis was also used to predict the secondary structure of the deduced amino acid sequence of P. motoro StAR (Kneller et al. 1990, McGuffin et al. 2000).

\section{Heterologous expression of $\boldsymbol{P}$. motoro StAR}

In order to examine the biological activity of the $P$. motoro StAR protein, we cotransfected green monkey kidney (COS-1) cells with P. motoro StAR/pCMV-5 and a human cholesterol side chain cleavage/adrenodoxin reductase/adrenodoxin fusion construct (the F2 construct, a generous gift of Dr Walter L Miller, University of California, San Francisco; for details regarding this construct please see Harikrishna et al. 1993). Initial studies indicated $P$. motoro StAR mRNA was expressed but poorly translated in mammalian cells. To increase the expression of $P$. motoro StAR in mammalian cells, we used PCR to mutate the wild-type translational start site of the $P$. motoro StAR coding sequence into a completely conserved Kozak's sequence (StAR Kozak S: 5'-GCCA CGATGGTTCGAGGCACTTTTAAGG-3'; Kozak's sequence underlined). In order to facilitate detection of the expressed protein in future studies, an antisense primer (StAR-HSV AS: 5'-TTCGGGGGGGAGTTC TGGGTGGCTGTAAGTGTTTGG-3') that destroys the wild-type 'stop' signal and introduces the first 24 nucleotides of the sequence encoding the 12 amino acid herpes simplex virus tag (HSV-tag) antigen was used in this initial PCR reaction. This reaction was diluted 1:100 and used as template for a second round of PCR with the StAR Kozak sense primer and an HSV-tag specific AS primer (HSV AS: 5'-AAGCTTCTAGAC TAATCGTCGGGGTCTTCGGGGGGGAG-3') that includes the last 24 nucleotides encoding the HSV antigen (overlapping 12 nucleotides of the StAR-HSV AS primer) followed by a stop signal (TAG) and HindIII and XbaI restriction sites. A high-fidelity thermostable polymerase was used in these reactions (Invitrogen Platinum Taq High Fidelity). PCR products were ligated into pCR II (Invitrogen) and sequenced to confirm sequence fidelity. Confirmed $P$. motoro StAR/pCR II constructs were digested with EcoRI and the liberated StAR insert was gel purified and ligated into EcoRI-digested pCMV5 vector. E. coli harboring pGMV5 constructs containing the StAR insert in the proper orientation were identified using a pCMV5specific sense primer and a $P$. motoro StAR-specific antisense primer. The $\mathrm{pCMV} / P$. motoro StAR construct was purified from an overnight culture and used to transfect COS-1 cells using a commercial transfection reagent (TransIT-COS; Mirus Bio Corporation, Madison, WI, USA). COS- 1 cells were plated into six-well plates to yield $60-80 \%$ confluency the following day, when two wells each were transfected with either empty pCMV5 $(0.5 \mu \mathrm{g})$, empty pCMV5 $(0.25 \mu \mathrm{g})$ and F2 $(0.25 \mu \mathrm{g})$, or $\mathrm{pCMV} 5 / P$. motoro $\operatorname{StAR}(0.25 \mu \mathrm{g})$ and F2 $(0 \cdot 25 \mu \mathrm{g})$. All wells also received $0 \cdot 1 \mu \mathrm{g} \mathrm{CMV} / \beta-$ galactosidase reporter construct. Cells received fresh media $24 \mathrm{~h}$ after transfection, which was subsequently collected $24 \mathrm{~h}$ later. Pregnenolone was measured in these samples using a commercial ELISA as per manufacturer's instructions (Diagnostics Biochem, Canada). Following collection of the media, cells were lysed in $250 \mu \mathrm{l}$ lysis buffer and $\beta$-galactosidase activity determined using a commercial kit (Promega) to establish transfection efficiency. Rates of pregnenolone synthesis normalized to $\beta$-galactosidase activity were $\log$ transformed and analyzed using ANOVA followed by Tukey's post-hoc test. Comparisons generating $P$ values less than 0.05 were considered significantly different.

\section{Northern blot analysis}

P. motoro interrenal gland total RNA $(10 \mu \mathrm{g})$ was denatured in $20 \mathrm{mM} 3$-[N-morpholino]propanesulfonic acid, $2 \mathrm{mM}$ sodium acetate and $1 \mathrm{mM}$ EDTA; $\mathrm{pH} 7 \cdot 0$ (MOPS buffer) with $2.5 \mathrm{M}$ formaldehyde and $50 \%$ formamide. RNA was heated at $55{ }^{\circ} \mathrm{C}$ for $60 \mathrm{~min}$ and chilled in ice water before adding gel-loading buffer $(10 \times$ gel loading buffer: $50 \%$ glycerol, $10 \mathrm{mM}$ EDTA, $0.25 \%$ bromophenol blue and $0.25 \%$ xylene cyanol $\mathrm{FF}$ ). Standards (5 $\mu \mathrm{g}$ Invitrogen 240-9500 bp RNA ladder) and samples were size fractionated by gel electrophoresis in a $1.5 \%$ agarose gel containing $1 \times$ MOPS buffer and $2 \cdot 2 \mathrm{M}$ formaldehyde for $2 \cdot 5 \mathrm{~h}$ (Sambrook et al. 1989). RNA was transferred to a Nytran SuPerCharge membrane using downward capillary action and cross-linked to the membrane by a 6 min exposure to UV light $(254 \mathrm{~nm})$. The membrane was prehybridized in North2South (Pierce) hybridization solution for $0.5 \mathrm{~h}$ and hybridized for $2 \mathrm{~h}$ with horseradish peroxidaselabeled probe generated by excising the full open reading frame of $P$. motoro StAR from the pCMV5 expression construct. The membrane was then washed three times in $2 \times$ standard sodium citrate $(0.3 \mathrm{M}$ sodium chloride, $0 \cdot 03 \mathrm{M}$ sodium citrate; $\mathrm{pH} 7 \cdot 0), 0 \cdot 1 \% \mathrm{SDS}$ for $5 \mathrm{~min}$, then three times in $2 \times$ standard sodium citrate for 5 min. All hybridizations and washes were conducted at $60{ }^{\circ} \mathrm{C}$ in a rotating hybridization oven. The membrane was then immersed in North2 South luminol/enhancer reagent (Pierce) for $5 \mathrm{~min}$ at room temperature, wrapped in plastic and exposed to autoradiography film for $1 \mathrm{~min}$. 


\section{Expression of StAR in $P$. motoro tissues}

RT-PCR was used to determine the tissue distribution of StAR expression in P. motoro. Total RNA, isolated from cerebellum, hypothalamus, pituitary, telencephalon, atrium, ventricle, gill, kidney, pancreas, spiral valve, liver, kidney, muscle, interrenal gland, ovary and testis was primed with random hexamers and used as template for RT as described above. These RT reactions were then used in PCR using the same primers used to generate the $P$. motoro StAR/pCMV5 expression construct described above. The thermal parameters for PCRs to determine tissue-specific StAR expression were: $95^{\circ} \mathrm{C}$ for $2 \mathrm{~min}$ followed by 35 cycles of $30 \mathrm{~s}$ at $95^{\circ} \mathrm{C}$, $30 \mathrm{~s}$ at $60{ }^{\circ} \mathrm{C}$ and $60 \mathrm{~s}$ at $72^{\circ} \mathrm{C}$. The quality of each RT reaction was assessed with $\mathrm{PCR}$ primers designed to amplify a $1100 \mathrm{bp}$ fragment of $P$. motoro $18 \mathrm{~S}$ RNA (sense: 5'-GGTACAGTGAAACTGCGAATGG-3'; antisense: 5'-TGGTGCGGTTCGGTCAATTCG-3') using the same thermal parameters. To ensure that the PCR products were not the result of genomic contamination, we performed reverse transcriptase-negative RT-PCR and PCR using P. motoro genomic DNA as template.

\section{Results}

\section{Isolation of $\boldsymbol{P}$. motoro StAR sequences}

The degenerate primers used in initial RT-PCR reactions were designed to amplify a $340 \mathrm{bp}$ fragment of StAR; a product of this size was obtained using $P$. hystrix interrenal gland RNA as template (data not shown). BLAST analysis (http://www.ncbi.nlm.nih.gov/ BLAST/) of this PCR product found similarity to other StAR sequences. Subsequent RACE reactions using primers designed to this sequence yielded the sequence of most (if not all) of the $P$. hystrix StAR transcript (data not shown, full sequence has been deposited in Genbank; accession no. AY553722). This transcript harbors an open reading frame beginning with a sequence (AGACACAAGATGATTCGA; initiation codon in italics) that agrees well with translational start motifs found in less derived vertebrates (Smutzer \& Chamberlin 1998). This open reading frame is $852 \mathrm{bp}$ in length and encodes a protein of 284 amino acids that contains a putative START domain, as indicated in BLAST analysis (Marchler-Bauer \& Bryant 2004).

RT-PCR and RACE reactions using $P$. hystrix and $P$. motoro StAR primers and $P$. motoro interrenal gland RNA as template yielded an open reading frame of $852 \mathrm{bp}$ that begins with the same translational start sequence found in $P$. hystrix StAR transcripts and encodes a protein that differs from the $P$. hystrix protein only at position 39, which is occupied by a lysine residue in $P$. hystrix and an arginine residue in $P$. motoro.

\section{Computer analysis of the freshwater stingray StAR} deduced amino acid sequence

Phylogenetic analysis of the putative freshwater stingray StAR and 32 other START proteins showed seven distinct protein families, STARD4, STARD5, STARD6, STARD10, STARD13, MLN64 and StAR. Freshwater stingray StAR proteins clearly segregate with other StAR proteins (Fig. 1). The putative freshwater stingray StAR proteins are almost identical in size to StAR proteins from other vertebrate classes and amino acid residues important to StAR function and regulation are also highly conserved (Fig. 2). Computer analysis (Kneller et al. 1990, McGuffin et al. 2000) of the deduced amino acid sequence of $P$. motoro StAR indicates a predicted secondary structure that is very similar to that of human StAR (not shown).

\section{Heterologous expression and activity of freshwater stingray StAR}

In addition to structural similarities, $P$. motoro StAR is similar in function to other known StAR proteins (Fig. 3). COS-1 cells transfected with the F2 construct produced $2.92 \pm 1 \cdot 14 \mathrm{ng}$ pregnenolone/h per well (mean of two wells from three independent transfections \pm S.E.M.). Coexpression of F2 with a pCMV5/P. motoro StAR construct significantly $(P<0 \cdot 01)$ increased the synthesis of pregnenolone to $47 \cdot 36 \pm 19 \cdot 06 \mathrm{ng}$ pregnenolone/h per well. COS- 1 cells transfected with empty pCMV5 produced $0 \cdot 17 \pm$ $0 \cdot 01 \mathrm{ng}$ pregnenolone/h per well, significantly less than either F2-transfected cells $(P<0 \cdot 05)$ or F2+StARtransfected cells $(P<0 \cdot 001)$.

\section{Characterization of $P$. motoro StAR mRNA expression}

Northern blot analysis revealed a single transcript of approximately $4000 \mathrm{bp}$ in $P$. motoro interrenal gland RNA (Fig. 4), slightly larger than the longest $P$. hystrix and $P$. motoro cDNAs isolated by RACE. The mRNA sequences encoding different START proteins within a species are not very similar. For example, when the StAR open reading frame is aligned with the open reading frame of the closely related MLN64, there is only $40 \%$ similarity between the human StAR and MLN64 sequences and only 33\% similarity between the mouse StAR and MLN64 sequences. Therefore, given the lack of similarity between sequences encoding START proteins within species and the stringent hybridization conditions employed in this study, we are confident that the single band in our Northern blot analysis represents the mRNA encoding $P$. motoro StAR.

StAR expression appears to be more robust in $P$. motoro interrenal gland of both sexes than in other tissues 


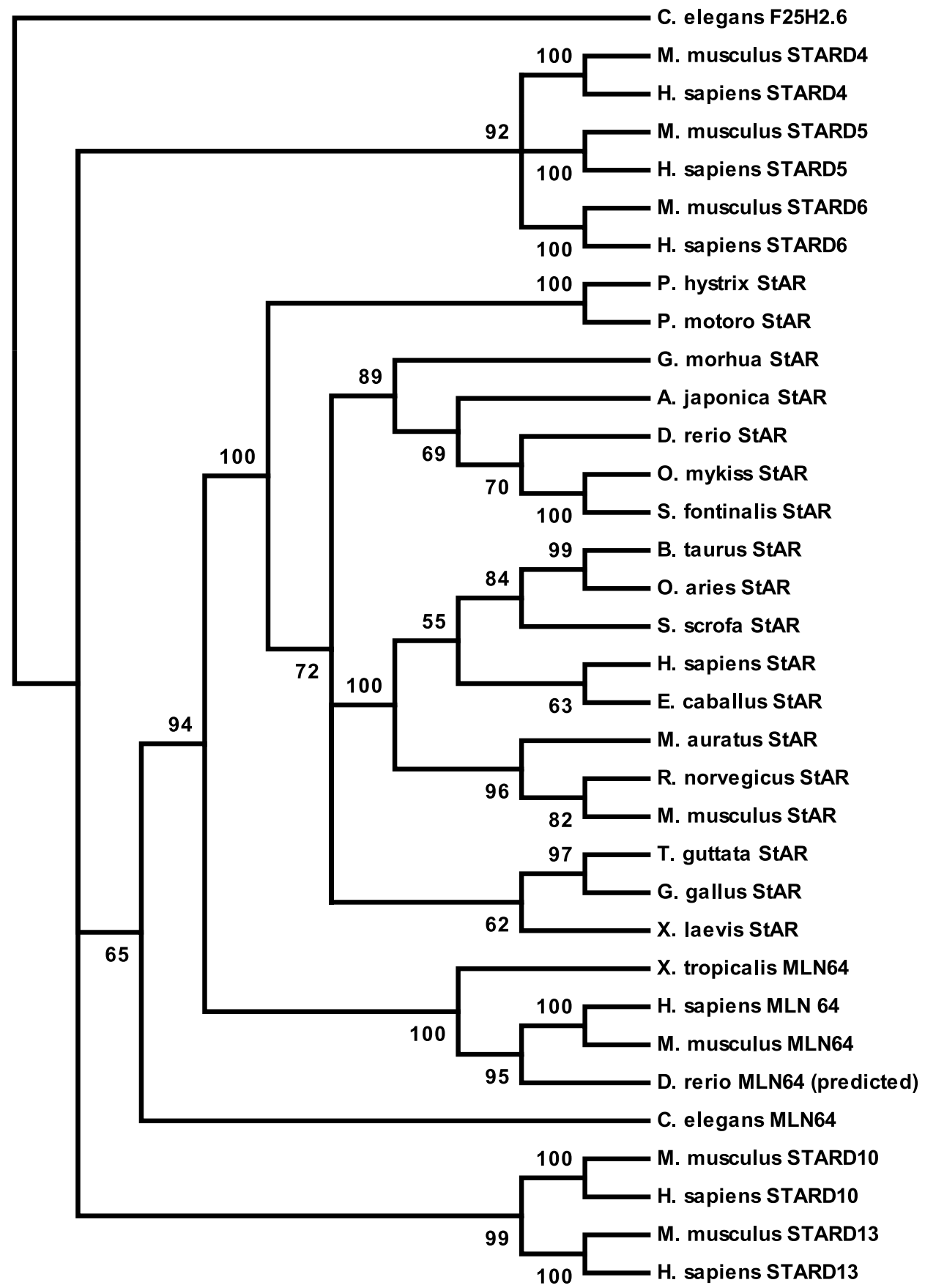

Figure 1 Molecular phylogeny of START proteins. The deduced amino acid sequences of $P$. hystrix and $P$. motoro StAR proteins were aligned with Salvelinus fontinalis (brook trout), Oncorhynchus mykiss (rainbow trout), Anguilla japonica (Japanese eel), Danio rerio (zebrafish), Gadus morhua (Atlantic cod), Xenopus laevis (African clawed frog), Gallus gallus (chicken), Taeniopygia guttata (zebrafinch), Mus musculus (mouse), Mesocricetus auratus (hamster), Rattus norvegicus (rat), Equus caballus (horse), Sus scrofa (pig), Ovis aries (sheep), Bos tarus (cow) and Homo sapiens (human) StAR proteins, C. elegans, zebrafish (predicted protein obtained from zebrafish database), Xenopus tropicalis, mouse and human MLN64, mouse and human STARD4, mouse and human STARD5, mouse and human STARD6, mouse and human STARD10, and mouse and human STARD13. The tree was rooted using the $C$. elegans F25H2.6 putative START protein. Please refer to Materials and methods for database accession numbers. Molecular phylogenetic analysis was then performed using the Neighbor Joining method (Saitou \& Nei 1987) in MEGA version 3 software (Kumar et al. 2004) and a bootstrap consensus tree generated. The numbers at branch points represent bootstrapping values obtained with 2000 bootstrap replicates. Branches not supported by bootstrapping values of at least $50 \%$ were condensed to produce a multifurcating tree. Freshwater stingray StAR proteins segregate with and assume a position basal to other StAR proteins. 

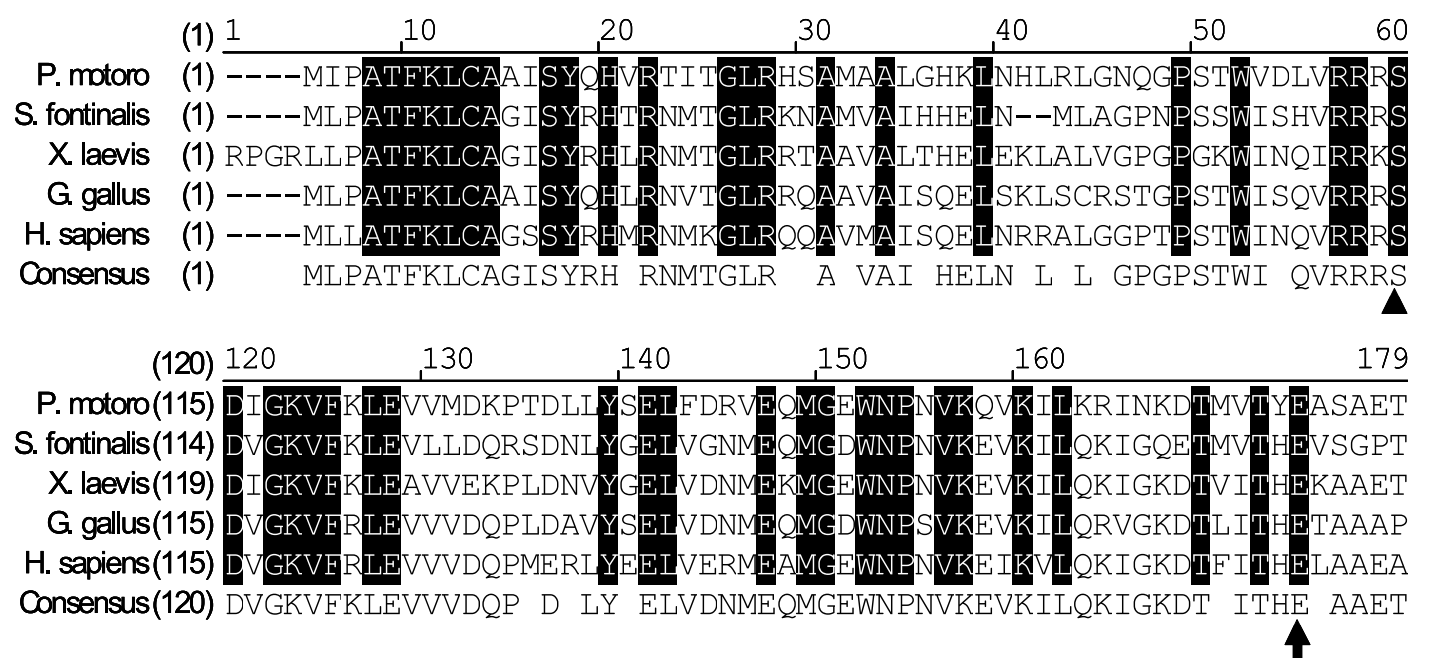

(180) 180

190

200

210

220

239

P. motoro(175) AGNVISPRDFVSVRYAKRRGSTCFLAGMAMHCNLMPQQNGFIRGENGPSCIVLCPSAEDP

S. fontinalis(174) PGNVVGPRDFVSVRCAKRRGSTCF

$X$ laevis(179) PGNIVGARDFVSVRCSKRRGSTC

G. gallus(175) PGNIVGPRDFVSVRCSRRRGSTCV

H. sapiens(175) AGNLVGPRDFVSVRCAKRRGSTCV

Consensus(180) PGN VGPRDFVSVRCAKRRGSTC

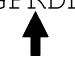

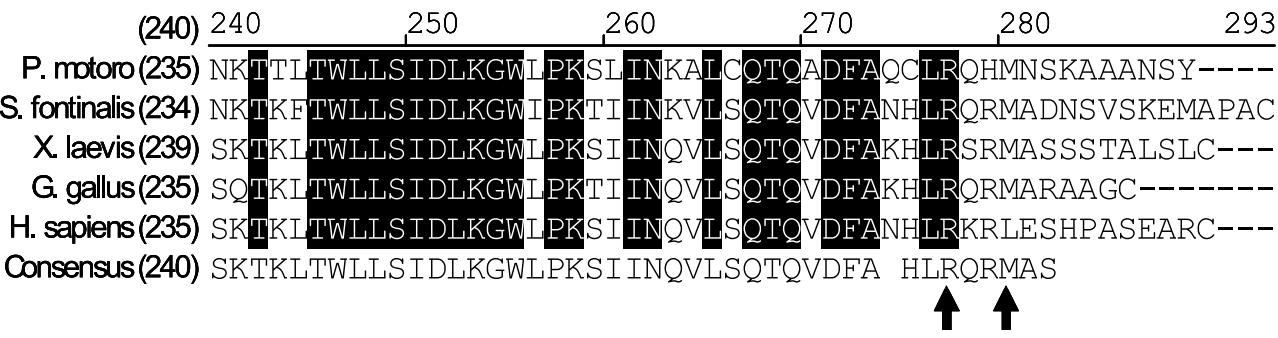

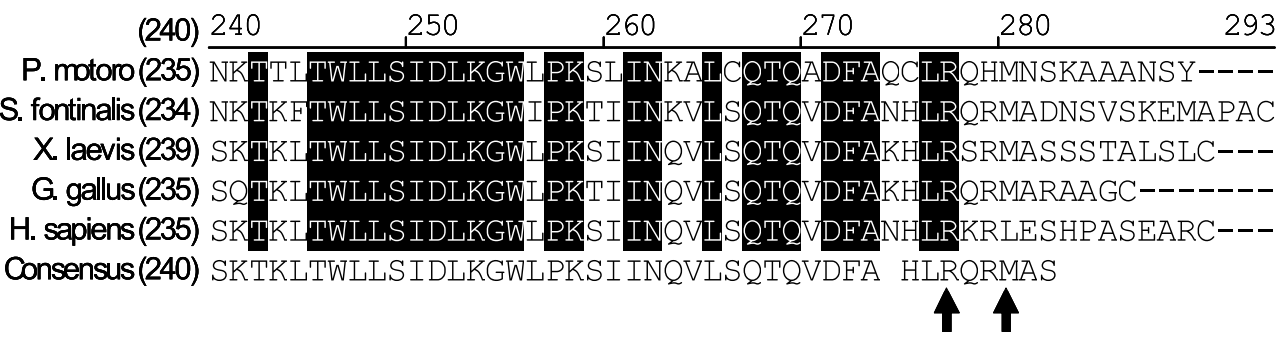

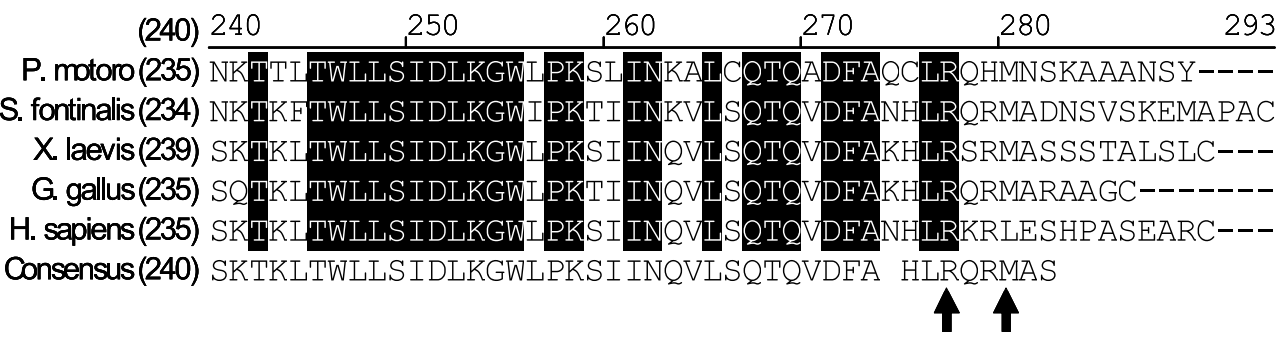

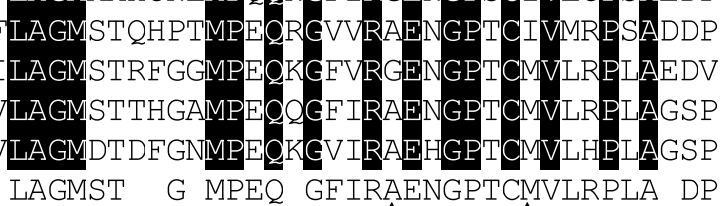

LAGMST

$G$ MPEQ GFIRAENGPTCM

Figure 2 Alignment of the deduced amino acid sequence of freshwater stingray StAR proteins with other StAR proteins. The deduced amino acid sequence of $P$. motoro StAR was aligned to StAR sequences from brook trout, African clawed frog, chicken and human StAR (please refer to Materials and methods for database accession numbers). The deduced amino acid sequence of $P$. hystrix StAR differs from $P$. motoro StAR only at position 39 (lysine in $P$. hystrix; arginine in $P$. motoro). Amino acid residues that are identical in all StAR proteins are white with black background. Dashes indicate spaces introduced to facilitate alignment. Amino acid residues that are known to disrupt STAR function when mutated are indicated by arrows (Stocco 2002), while arrowheads indicate potential sites of serine phosphorylation that may be important to the regulation of StAR activity (Arakane et al. 1997). Importantly, computer analysis (Marchler-Bauer \& Bryant 2004) identified a putative START domain between residues 72 and 275 of the P. motoro StAR protein.

(Fig. 5). In female P. motoro, StAR expression was also detected in the atrium, ventricle, gill, muscle and ovary. StAR transcripts can be detected in pituitary and telencephalon samples after 40 PGR cycles (not shown). In male P. motoro, StAR mRNA was detected in atrium, ventricle and testis. A weak band appears in the pituitary after 40 PCR cycles (not shown). StAR mRNA was not detected in P. motoro cerebellum, hypothalamus (Fig. 5), spiral valve, pancreas, liver or kidney (not shown). Templates used in these reactions were found to be of similar quality as determined by amplification of $18 \mathrm{~S}$ sequence (Fig. 5). No amplification of StAR occurred in
PGR reactions using either $P$. motoro genomic DNA or reverse transcriptase-negative RT reactions as template (data not shown), which indicates that genomic DNA did not serve as template in StAR RT-PCRs.

\section{Analysis of the UTRs of freshwater stingray StAR transcripts}

In $P$. hystrix, the longest $5^{\prime}$-RACE products yielded only $38 \mathrm{bp}$ of $5^{\prime}$-UTR. The $P$. hystrix StAR 3'-UTR is $2472 \mathrm{bp}$ in length (excluding the poly-A tail) and contains a consensus polyadenylation signal (AATAAA) 


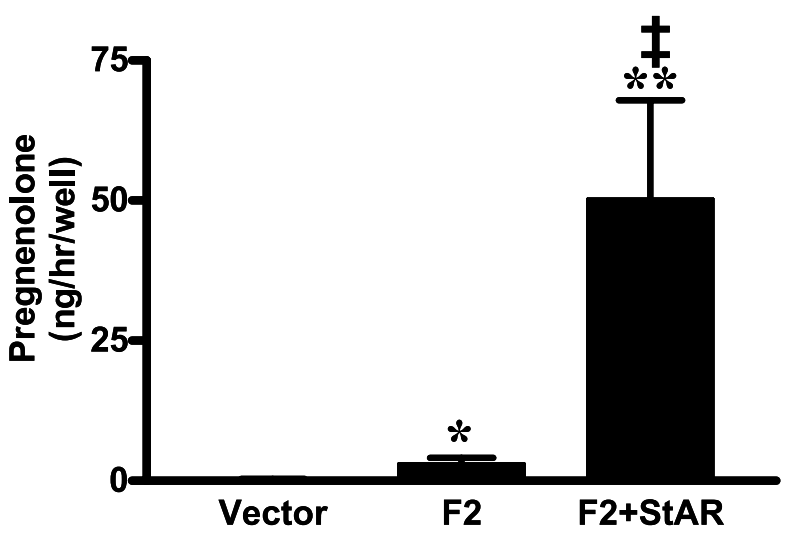

Figure 3 Heterologous expression of $P$. motoro StAR in COS-1 cells. Green monkey kidney cells (COS-1) transfected with a human side chain cleavage/adrenodoxin reductase/adrenodoxin fusion construct (the F2 construct (Harikrishna et al. 1993)) and a P. motoro StAR/pCMV-5 expression construct produced pregnenolone at a significantly higher rate $(47.36 \pm 19.06 \mathrm{ng}$ pregnenolone/h per well) than cells transfected with $\mathrm{F} 2$ alone $(2.92 \pm 1.14 \mathrm{ng}$ pregnenolone/h per well). COS- 1 cells transfected with empty pCMV-5 produced significantly less pregnenolone $(0.17 \pm 0.01 \mathrm{ng}$ pregnenolone/h per well). All cells were transfected with equal amounts of a $\beta$-galactosidase expression construct and rates of pregnenolone synthesis were normalized to $\beta$-galactosidase activity to control for transfection efficiency. Bars represent the means of six wells from three independent transfections and error bars represent S.E.M. A single asterisk indicates a significant difference $(P<0.05)$ from pCMV5-transfected cells; a double asterisk indicates a significant difference $(P<0.01)$ from pCMV5-transfected cells and a double dagger indicates a significant difference $(P<0.001)$ from pCMV5+F2-transfected cells, as determined by one-way ANOVA followed by Tukey's post-hoc test.

20 bp upstream of a poly-A tail. As in P. hystrix, the longest $P$. motoro $5^{\prime}$-RACE products yielded $38 \mathrm{bp}$ of 5'-UTR sequence. RT-PCR and 3'-RACE yielded two overlapping $P$. motoro StAR 3'-UTR sequences (the full sequences have been deposited in Genbank; accession numbers AY553721 and AY553723). The shorter $P$. motoro StAR 3'-UTR is 379 bp in length (excluding the poly-A tail) and includes an atypical polyadenylation signal (CATAAA) $13 \mathrm{bp}$ from the poly-A tail. The longer P. motoro StAR 3'-UTR (2472 bp in length excluding the poly-A tail) completely overlaps and extends the shorter transcript. A consensus polyadenylation signal (AATAAA) is found $19 \mathrm{bp}$ from the poly-A tail in this transcript. The $3^{\prime}$-UTR does not harbor additional open reading frames of greater than 60 codons. The $3^{\prime}$-UTR of the P. motoro was scanned for possible structural and regulatory motifs using RNA analysis software (http:// wb2x01.biozentrum.uni-wuerzburg.de/) (Bengert \& Dandekar 2003), but no such motifs were detected. However, BLAST analysis of the long 3 '-UTR revealed the presence of a sequence very similar to a short interspersed repetitive element (HE1 SINE) found in

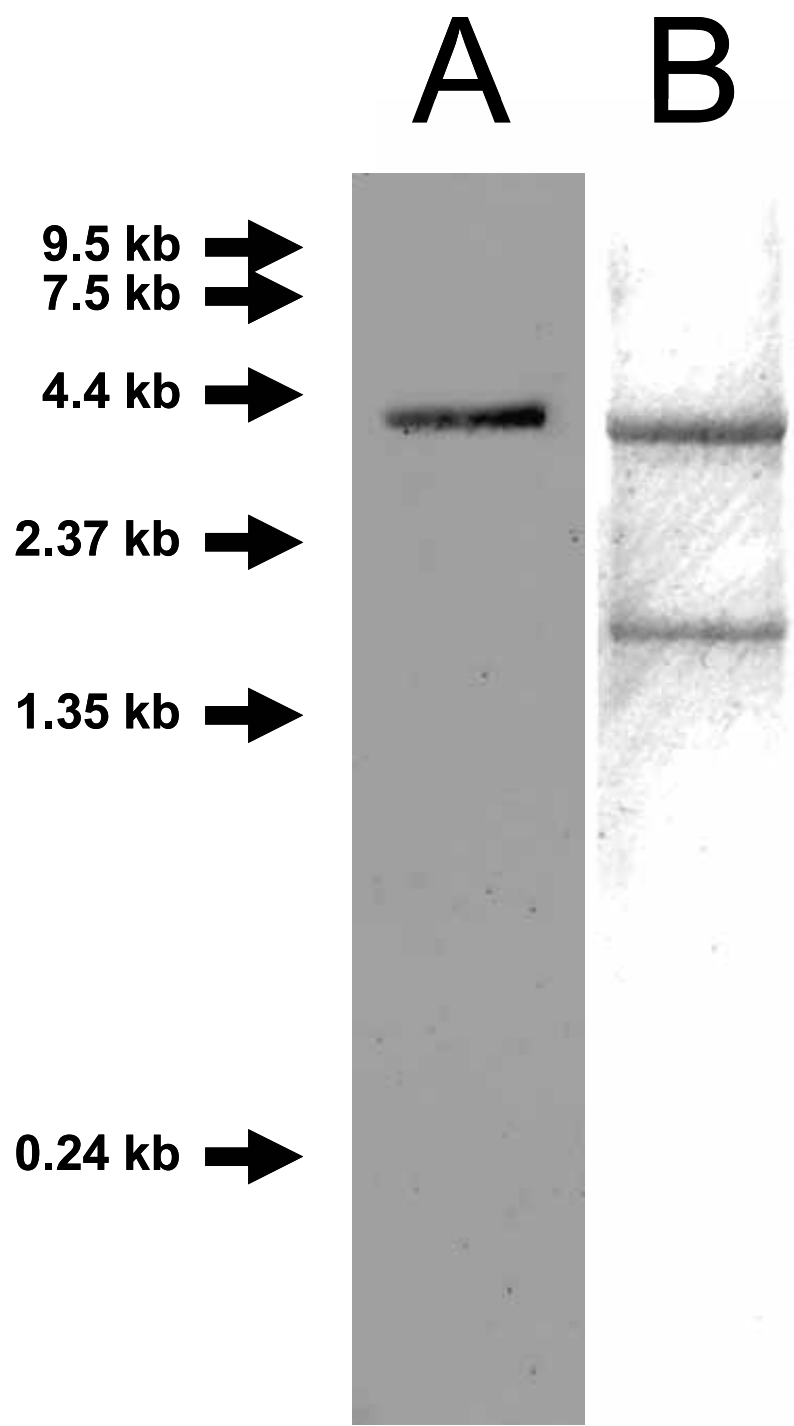

Figure 4 Northern blot analysis of StAR expression in freshwater stingray interrenal gland. Northern blot analysis (lane A) of $P$. motoro interrenal gland total RNA indicates a single StAR transcript of approximately $4000 \mathrm{bp}$. The positions of RNA standards are shown to the left of lane A and a negative image of the pretransfer ethidium bromide-stained interrenal gland RNA is shown in lane B.

elasmobranchs and other vertebrates (Ogiwara et al. 1999). Compared with other elasmobranchs, the putative $P$. motoro StAR 3'-UTR SINE sequence is $39 \%$ and $48 \%$ identical to those of Mustelus manazo and Scyliorhinus torazame respectively (Fig. 6).

\section{Discussion}

Our molecular phylogenetic analysis of 34 START proteins clusters the $P$. hystrix and P. motoro proteins with 

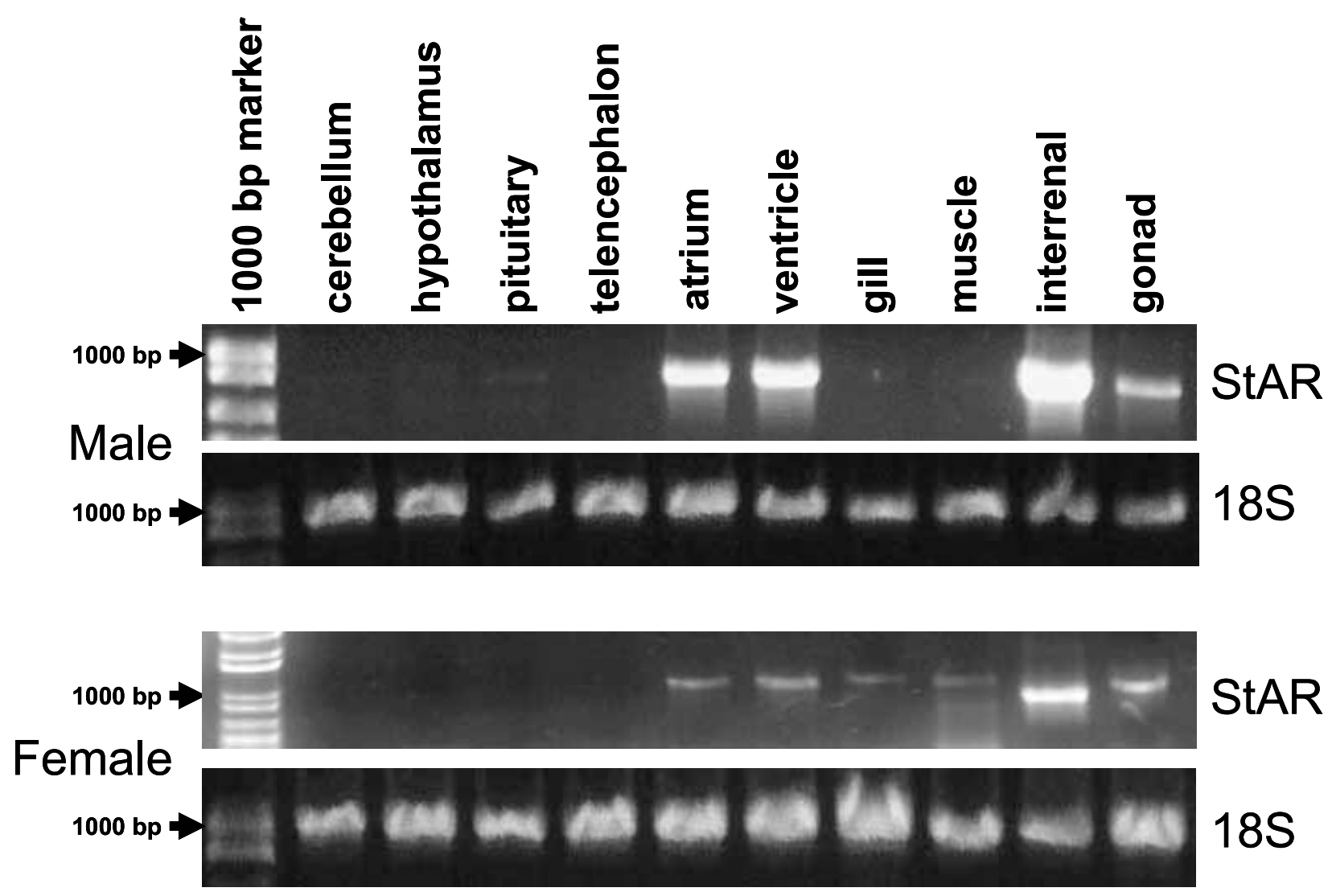

Figure 5 Expression of StAR mRNA in $P$. motoro tissues. RT-PCR revealed the expression of StAR in multiple tissues from male and female $P$. motoro. In addition to classic steroidogenic tissues such as the interrenal gland and gonadal tissues, StAR mRNA is also detected in the heart of both sexes and in the gill and muscle of female $P$. motoro. Forty PCR cycles were necessary to detect StAR mRNA in the brain. StAR mRNA was not detected in kidney, liver, spiral valve and pancreas of $P$. motoro. Primers designed to amplify approximately $1100 \mathrm{bp}$ of $18 \mathrm{~S}$ RNA were used in separate RT-PCR reactions to ensure template quality. The position of the $1000 \mathrm{bp}$ DNA standard is indicated by the arrows to the left of each image. Reverse transcriptase-negative reactions and reactions using $P$. motoro genomic DNA as template were used to ensure StAR amplicons were not amplified from contaminating genomic DNA (not shown).

the StAR family. The START protein with the greatest sequence similarity to StAR is MLN64, but MLN64 proteins cluster separately from StAR proteins. The freshwater stingray StAR proteins are also of similar size and show high identity (56-64\%) when compared with other StAR proteins. The amino acid residues that are critical to StAR function and regulation (e.g. the serine phosphorylation motif at Ser195) are highly conserved between freshwater stingray StAR proteins and other StAR proteins. In addition, the predicted secondary structures of $P$. motoro and human StAR are similar, with an N-terminal amphipathic helix that may serve as a mitochondrial targeting sequence (Kallen et al. 1998). Most of the remaining protein consists of alternating alpha helices and beta strand motifs thought to form the START domain, a hydrophobic tunnel that can bind to a single molecule of cholesterol (Tsujishita \& Hurley 2000). Moreover, the P. motoro StAR protein can facilitate the synthesis of pregnenolone by SCG, as indicated by transfection assays in COS-1 cells cotransfected with the F2 human SCG electron transport chain construct. The fusion of a green fluorescent protein (GFP) to the C-terminus of ovine StAR significantly lowers steroidogenic activity (West et al. 2001). The addition of a C-terminal HSV-tag might have similar effects on the activity of the P. motoro StAR protein. However, the HSV-tag (12 amino acids) is significantly smaller than GFP (238 amino acids); we therefore expect the HSV-tag has minimal effects on StAR activity. In any case, the $P$. motoro StAR/HSV-tag fusion protein has significant steroidogenic activity.

Like StAR, MLN64 can facilitate steroidogenesis; however, MLN64 proteins (about 450 residues) are much larger than StAR proteins (about 280 residues), are not typically targeted to the mitochondria (Moog-Lutz et al. 1997, Watari et al. 1997), and are less similar to the deduced freshwater stingray proteins (19-57\%). These 


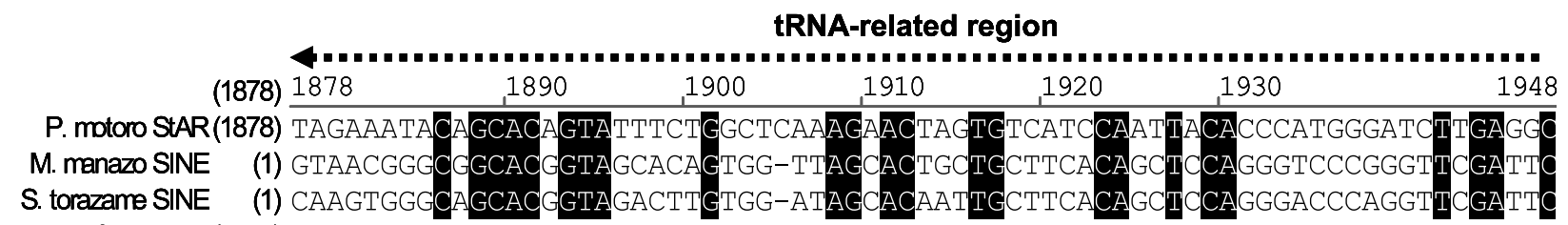

Consensus(1878) AAA GGGCAGCACGGTAG CTGTGG ATAGCACTA TGCTTCACAGCTCCAGGGACCCGGGTTCGATTC

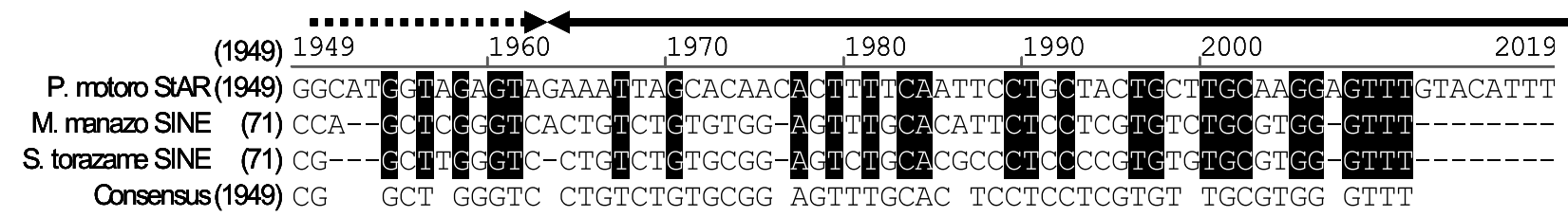

central conserved region
con

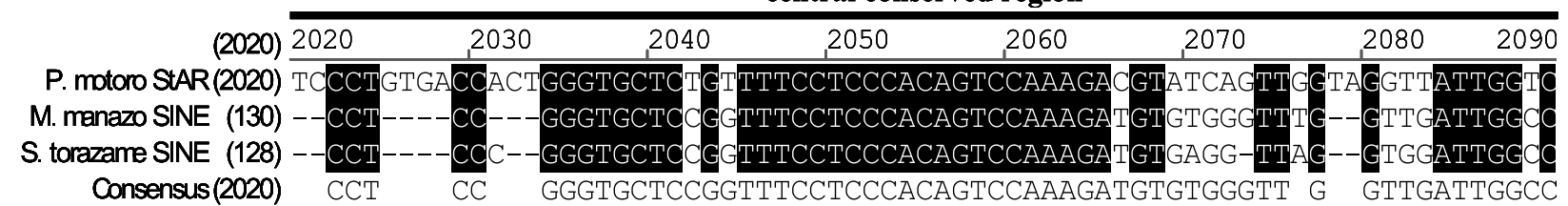

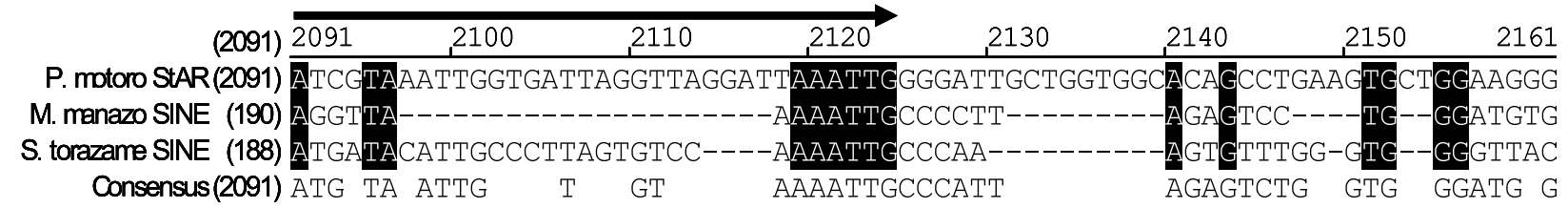

Figure 6 The long form of the P. motoro StAR transcript contains a short interspersed repetitive element. BLAST analysis revealed significant homology between $P$. motoro StAR 3'-UTR sequence 1878-2161 bp and the HE1 family of short interspersed repetitive elements (SINEs) found in the gummy shark (Mustelus manazo; Genbank accession no. AB027719), the cloudy cat shark (Scyliorhinus torazame; Genbank accession no. AB027721) and other elasmobranch species (Ogiwara et al. 1999). The positions of the tRNA-related (dashed line) and central conserved (solid line) regions commonly found in SINEs are indicated above the nucleotide sequence.

findings strongly support the conclusion that we have isolated cDNAs encoding P. hystrix and P. motoro StAR.

A single, large StAR transcript (approximately $4000 \mathrm{bp}$ ) was detected in $P$. motoro interrenal gland, slightly larger than the longest cDNA clone isolated in this species (3365 bp). Repeated attempts to extend the $5^{\prime}$ - and $3^{\prime}$-UTRs did not yield additional sequence. While it is possible that we are still lacking untranslated sequence, it is also likely that the difference between the results of northern blot analysis and the length of isolated RACE clones is due to polyadenylation, because poly-A tails can be several hundred nucleotides in length (MacDonald \& Redondo 2002). The majority of the P. motoro StAR transcript is $3^{\prime}$-UTR sequence, which contains three consensus polyadenlyation signals (beginning at 2125, 2130 and $3341 \mathrm{bp}$ ). Other elasmobranch steroidogenic enzymes have exceedingly long 3'-UTR sequences with multiple polyadenylation signals. For example, southern stingray (Dasyatis americana) SCG is encoded by a large mRNA that includes $3000 \mathrm{bp}$ of 3'-UTR with four consensus polyadenylation signals (Nunez \& Trant 1997). Similarly, D. americana
$3 \beta$-hydroxysteroid dehydrogenase mRNA contains at least $1000 \mathrm{bp}$ of $3^{\prime}$-UTR with two consensus polyadenylation signals (Nunez \& Trant 1998).

These differences in 3'-UTR length may have an influence on the function of translated enzymes. For example, $D$. sabina aromatase is encoded by two overlapping transcripts (1700 and $3100 \mathrm{bp}$ ) that apparently result from the use of different polyadenylation signals; when these transcripts were expressed in COS cells, the $1700 \mathrm{bp}$ form produced twice the aromatase activity of the $3100 \mathrm{bp}$ form (Ijiri et al. 2000). The short P. motoro StAR transcript (1324 bp) isolated by 3 '-RACE may result from the use of an atypical polyadenylation signal (CATAAA) starting at $1306 \mathrm{bp}$. StAR transcripts of multiple sizes are common in other vertebrates, including zebrafish (1500, 2500 and $4500 \mathrm{bp})$, rainbow trout (2300, 4300 and $9900 \mathrm{bp})$ and humans (1600, 4400 and 7500 bp) (Sugawara et al. 1995b, von Hofsten et al. 2002, $\mathrm{Li}$ et al. 2003). The rapid induction of steroidogenesis by peptide hormones and other factors depends on the translation of StAR mRNA, but not on StAR gene transcription, which implies that a significant pool of 
StAR mRNA must be maintained in steroidogenic cells (Stocco \& Clark 1996). The extensive 3'-UTRs present in StAR and other steroidogenic mRNAs may stabilize these molecules, thus allowing a ready pool of mRNA that can be rapidly translated to augment steroidogenic capacity. The poly-A tail of mRNA and the poly-A binding proteins that bind it are known to protect mRNAs from degradation by exonucleases (for review see Day \& Tuite 1998). Lengthy 3'-UTR sequences with multiple polyadenylation signals could act as a buffer against degradation, perhaps further extending the half-life of these mRNA transcripts (Littauer \& Soreq 1982, Leff et al. 1986).

Analysis of the 3'-UTR of freshwater stingray StAR transcripts indicates the presence of a well-conserved elasmobranch HE1 SINE (Ogiwara et al. 1999). To the best of our knowledge, at least one example of an interspersed repetitive element altering the expression of a steroidogenic enzyme has been published; i.e. a retroviral long terminal repeat was discovered in the aromatase promoter of chicken strains that display the henny-feathering trait (Matsumine et al. 1991, McPhaul et al. 1991). This promoter is apparently responsible for the extragonadal expression of aromatase in these chickens. Although speculative, it is possible that the SINE sequence in freshwater stingray StAR has important physiological consequences. For example, the transcription of some SINE sequences is induced by cellular stress and high levels of SINE RNA molecules have been shown to inhibit the ability of the double-stranded RNA-dependent protein kinase (PKR) to inhibit translation (Liu et al. 1995, Schmid 1998). Other studies have revealed that SINE sequences can activate a PKR-independent pathway that stimulates the translation of newly transcribed mRNA (Rubin et al. 2002). StAR SINE sequences could augment translation through induction in response to stress, inhibition of PKR and induction of PKR-independent pathways. The presence of a SINE-like sequence in the freshwater stingray StAR 3'-UTR is of interest because the adrenocortical response to ACTH depends on a rapid increase in StAR translation, and sustained steroidogenesis depends on efficient translation of newly transcribed StAR mRNA (Stocco 2001).

In freshwater stingrays, StAR is expressed in several tissues, including those of the nervous, cardiovascular and reproductive systems. These data are consistent with studies in other vertebrates that demonstrate StAR expression is not restricted to adrenocortical and gonadal tissue. For example, in mammals, StAR mRNA has been detected in human fetal and adult kidney (Sugawara et al. 1995a), and in glial and neuronal cells of the cerebellum, hypothalamus and other regions of the human brain (King et al. 2002). Using northern blot analysis, Bauer et al. (2000) detected StAR mRNA in the head of a teleost (zebrafish), but not in the brain of the chicken; StAR transcripts were also detected in the zebrafish kidney, although this could be due to the inclusion of adrenocortical cells of the head kidney (the interrenal gland of teleosts). StAR expression was detected by northern blot and RT-PCR analysis in rainbow trout pyloric ceca, intestine and spleen in addition to head kidney and gonadal tissue, but only in traditional steroidogenic tissues (head kidney and gonads) in brook trout (Kusakabe et al. 2002a).

In freshwater stingrays, the detection of StAR expression in extragonadal and extraadrenocortical tissues, such as the heart, gill and muscle, is significant because these tissues do not express SCG mRNA (B S N Nunez and S L Applebaum, unpublished observations) and therefore cannot convert cholesterol to pregnenolone. In contrast, most extragonadal and extraadrenocortical tissues in mammals that express StAR (e.g. brain, heart) also express SCC and are therefore able to produce steroids (King et al. 2002, White 2003). StAR activity is not specific to steroidogenesis, but can increase the activity of other cholesterol-metabolizing enzymes such as cholesterol 27-hydroxylase (Sugawara et al. 1995a). StAR is expressed in the human kidney, a tissue that does not express $\mathrm{SCG}$, but does produce steroid-like molecules (e.g. vitamin $\mathrm{D}$ hormones). The fact that StAR is expressed in tissues such as $P$. motoro heart, muscle and gill, rainbow trout pyloric ceca, intestine and spleen and human (and potentially zebrafish) kidney is an indication that StAR may be important to other biosynthetic pathways that utilize cholesterol. Of particular interest is the synthesis of endogenous cardiac glycosides (e.g. ouabain, digoxin, bufadienolides), cholesterol derivatives which can have both rapid (through interaction with the sodium/potassium-ATPase) and long-term (through the induction of gene expression and cell proliferation) effects on ionoregulation and cardiovascular function (Schoner 2002). Although their biosynthetic pathways have not been fully elucidated (Hamlyn 2004), there is evidence that several enzymes (including SCG) may be common to the synthesis of some cardiac glycosides and corticosteriods (Hamlyn et al. 2003). However, the synthesis of bufadienolide in mammals appears to be independent of both StAR and SCG, as indicated by studies using mouse Y-1 adrenocortical cells transfected with genes that inhibit the expression of StAR and SCG (Dmitrieva et al. 2000). Recent work suggests that endogenous cardiac glycosides may have an important role in the regulation of ionoregulation in fishes. A significant increase in immunoreactive plasma ouabain was detected in tilapia at 4 and $24 \mathrm{~h}$ following transfer from freshwater to seawater and $4 \mathrm{~h}$ after transfer from seawater to freshwater (Kajimura et al. 2004). This study found high concentrations of ouabain in extracts of several tissues, with the highest concentrations found in the interrenal gland (unfortunately the heart was not 
examined). The effects of ouabain in tilapia are dose dependent, as concentrations which do not inhibit sodium/potassium-ATPase $(10-100 \mathrm{pM})$ significantly inhibit the release of prolactin from the tilapia pituitary, while concentrations that inhibit sodium/potassiumATPase $(100-1000 \mathrm{nM})$ stimulate prolactin release (Kajimura et al. 2005). Therefore, while StAR may not have a role in bufadienolide synthesis, there is a good possibility that StAR (or another START protein) is involved in the regulated synthesis of cardiac glycosides.

\section{Acknowledgements}

We would like to thank Dr Walter L Miller of The University of California, San Francisco, for the generous gift of the F2 construct and Dr David Foltz of Louisiana State University for assistance with molecular phylogenetic analysis. The authors declare that there is no conflict of interest that would prejudice the impartiality of this scientific work.

\section{References}

Anderson WG, Cerra MC, Wells A, Tierney ML, Tota B, Takei Y \& Hazon N 2001 Angiotensin and angiotensin receptors in cartilaginous fishes. Comparative Biochemistry and Physiology Part A: Molecular and Integrative Physiology 128 31-40.

Arakane F, King SR, Du Y, Kallen CB, Walsh LP, Watari H, Stocco DM \& Strauss JF 3rd 1997 Phosphorylation of steroidogenic acute regulatory protein (StAR) modulates its steroidogenic activity. Fournal of Biological Chemistry 272 32656-32662.

Armour KJ, O'Toole LB \& Hazon N 1993 Mechanisms of ACTHand angiotensin II-stimulated $1 \alpha$-hydroxycorticosterone secretion in the dogfish, Scyliorhinus canicula. Fournal of Molecular Endocrinology $10235-244$

Bauer MP, Bridgham JT, Langenau DM, Johnson AL \& Goetz FW 2000 Conservation of steroidogenic acute regulatory (StAR) protein structure and expression in vertebrates. Molecular and Cellular Endocrinology 168 119-125.

Bengert P \& Dandekar T 2003 A software tool-box for analysis of regulatory RNA elements. Nucleic Acids Research 31 3441-3445.

Carrier JC \& Evans DH 1973 Ion and water turnover in the fresh-water elasmobranch Potamotrygon sp. Comparative Biochemistry and Physiology A 45 667-670.

Day DA \& Tuite MF 1998 Post-transcriptional gene regulatory mechanisms in eukaryotes: an overview. Fournal of Endocrinology $157361-371$

Dmitrieva RI, Bagrov AY, Lalli E, Sassone-Corsi P, Stocco DM \& Doris PA 2000 Mammalian bufadienolide is synthesized from cholesterol in the adrenal cortex by a pathway that is independent of cholesterol side-chain cleavage. Hypertension $36442-448$.

Ferguson JJ 1962 Puromycin and adrenal responsiveness to adrenocorticotropic hormone. Biochimica et Biophysica Acta 57 616-617.

Ferguson JJ 1963 Protein synthesis and adrenocorticotropin responsiveness. Fournal of Biological Chemistry $2382754-2759$.

Garren LD, Ney RL \& Davis WW 1965 Studies on the role of protein synthesis in the regulation of corticosterone production by adrenocorticotropic hormone in vivo. PNAS 53 1443-1450.

Garren LD, Davis WW, Crocco RM \& Ney RL 1966 Puromycin analogs: action of adrenocorticotropic hormone and the role of glycogen. Science 152 1386-1388.
Gerst JW \& Thorson TB 1977 Effects of saline acclimation on plasma electrolytes, urea excretion, and hepatic urea biosynthesis in a freshwater stingray, Potamotrygon sp. Garman, 1877. Comparative Biochemistry and Physiology A 56 87-93.

Geslin M \& Auperin B 2004 Relationship between changes in mRNAs of the genes encoding steroidogenic acute regulatory protein and $\mathrm{P} 450$ cholesterol side chain cleavage in head kidney and plasma levels of cortisol in response to different kinds of acute stress in the rainbow trout (Oncorhynchus mykiss). General and Comparative Endocrinology 135 70-80.

Hamlyn JM 2004 Biosynthesis of endogenous cardiac glycosides by mammalian adrenocortical cells: three steps forward. Clinical Chemistry $\mathbf{5 0} 469-470$.

Hamlyn JM, Laredo J, Shah JR, Lu ZR \& Hamilton BP 2003 11-hydroxylation in the biosynthesis of endogenous ouabain: multiple implications. Annals of the New York Academy of Sciences $\mathbf{9 8 6}$ 685-693.

Harikrishna JA, Black SM, Szklarz GD \& Miller WL 1993 Construction and function of fusion enzymes of the human cytochrome P450 scc system. DNA and Cell Biology 12 371-379.

Hazon N \& Henderson IW 1985 Factors affecting the secretory dynamics of $1 \alpha$-hydroxycorticosterone in the dogfish, Scyliorhinus canicula. General and Comparative Endocrinology 59 50-55.

Idler DR \& Truscott B 1966 1 $\alpha$-hydroxycorticosterone from cartilaginous fish: a new adrenal steroid in blood. Fournal of the Fisheries Research Board of Canada 23 615-619.

Idler DR, Freeman HC \& Truscott B 1967 Biological activity and protein-binding of $1 \alpha$-hydroxycorticosterone: an interrenal steroid in elasmobranch fish. General and Comparative Endocrinology 9 207-213.

Ijiri S, Berard C \& Trant JM 2000 Characterization of gonadal and extra-gonadal forms of the cDNA encoding the Atlantic stingray (Dasyatis sabina) cytochrome P450 aromatase (CYP19). Molecular and Cellular Endocrinology 164 169-181.

Kajimura S, Hirano T, Moriyama S, Vakkuri O, Leppaluoto J \& Grau EG 2004 Changes in plasma concentrations of immunoreactive ouabain in the tilapia in response to changing salinity: is ouabain a hormone in fish? General and Comparative Endocrinology 135 90-99.

Kajimura S, Seale AP, Hirano T, Cooke IM \& Grau EG 2005 Physiological concentrations of ouabain rapidly inhibit prolactin release from the tilapia pituitary. General and Comparative Endocrinology 143 240-250.

Kallen CB, Billheimer JT, Summers SA, Stayrook SE, Lewis M \& Strauss JF 3rd 1998 Steroidogenic acute regulatory protein (StAR) is a sterol transfer protein. Fournal of Biological Chemistry $\mathbf{2 7 3}$ 26285-26288.

King SR, Manna PR, Ishii T, Syapin PJ, Ginsberg SD, Wilson K, Walsh LP, Parker KL, Stocco DM, Smith RG et al. 2002 An essential component in steroid synthesis, the steroidogenic acute regulatory protein, is expressed in discrete regions of the brain. fournal of Neuroscience 22 10613-10620.

Klesch WL \& Sage M 1973 The control of the interrenal by the pituitary in the elasmobranch, Dasyatis sabina. Comparative Biochemistry and Physiology 45A 961-967.

Kneller DG, Cohen FE \& Langridge R 1990 Improvements in protein secondary structure prediction by an enhanced neural network. Fournal of Molecular Biology 214 171-182.

Kumar S, Tamura K \& Nei M 2004 MEGA3: Integrated software for molecular evolutionary genetics analysis and sequence alignment. Briefings in Bioinformatics 5 150-163.

Kusakabe M, Todo T, McQuillan HJ, Goetz FW \& Young G 2002a Characterization and expression of steroidogenic acute regulatory protein and MLN64 cDNAs in trout. Endocrinology 143 2062-2070.

Kusakabe M, Kobayashi T, Todo T, Mark Lokman P, Nagahama Y \& Young G 2002b Molecular cloning and expression during spermatogenesis of a cDNA encoding testicular $11 \beta$-hydroxylase $(\mathbf{P} 45011 \beta)$ in rainbow trout (Oncorhynchus mykiss). Molecular Reproduction and Development 62 456-469. 
Leff SE, Rosenfeld MG \& Evans RM 1986 Complex transcriptional units: diversity in gene expression by alternative RNA processing. Annual Review of Biochemistry 55 1091-1117.

Li YY, Inoue K \& Takei Y 2003 Steroidogenic acute regulatory protein in eels: cDNA cloning and effects of ACTH and seawater transfer on its mRNA expression. Zoological Science 20 211-219.

Littauer UZ \& Soreq H 1982 The regulatory function of poly(A) and adjacent $3^{\prime}$ sequences in translated RNA. Progress in Nucleic Acid Research and Molecular Biology 27 53-83.

Liu WM, Chu WM, Choudary PV \& Schmid CW 1995 Cell stress and translational inhibitors transiently increase the abundance of mammalian SINE transcripts. Nucleic Acids Research 23 1758-1765.

MacDonald CC \& Redondo JL 2002 Reexamining the polyadenylation signal: were we wrong about AAUAAA? Molecular and Cellular Endocrinology 190 1-8.

Marchler-Bauer A \& Bryant SH 2004 CD-Search: protein domain annotations on the fly. Nucleic Acids Research 32 W327-W331.

Matsumine H, Herbst MA, Ou SH, Wilson JD \& McPhaul MJ 1991 Aromatase mRNA in the extragonadal tissues of chickens with the henny-feathering trait is derived from a distinctive promoter structure that contains a segment of a retroviral long terminal repeat. Functional organization of the Sebright, Leghorn, and Campine aromatase genes. Fournal of Biological Chemistry 266 19900-19907.

McGuffin LJ, Bryson K \& Jones DT 2000 The PSIPRED protein structure prediction server. Bioinformatics 16 404-405.

McPhaul MJ, Matsumine H, Herbst MA \& Wilson JD 1991 Aromatase expression in extragonadal tissues of the Sebright chicken is controlled by a retroviral promoter. Transactions of the Association of American Physicians 104 141-149.

Moog-Lutz C, Tomasetto C, Regnier CH, Wendling C, Lutz Y, Muller D, Chenard MP, Basset P \& Rio MC 1997 MLN64 exhibits homology with the steroidogenic acute regulatory protein (STAR) and is over-expressed in human breast carcinomas. International Fournal of Cancer 71 183-191.

Nunez S \& Trant JM 1997 Isolation of the putative cDNA encoding cholesterol side chain cleavage cytochrome P450 (CYP11A) of the southern stingray (Dasyatis americana). Gene 187 123-129.

Nunez BS \& Trant JM 1998 Molecular biology and enzymology of elasmobranch $3 \beta$-hydroxysteroid dehydrogenase. Fish Physiology and Biochemistry 19 293-304.

Nunez BS \& Trant JM 1999 Regulation of interrenal steroidogenesis in the Atlantic stingray (Dasyatis sabina). Foumal of Experimental Zoology 284 517-525.

Ogiwara I, Miya M, Ohshima K \& Okada N 1999 Retropositional parasitism of SINEs on LINEs: identification of SINEs and LINEs in elasmobranchs. Molecular Biology and Evolution 16 1238-1250.

Rubin CM, Kimura RH \& Schmid CW 2002 Selective stimulation of translational expression by Alu RNA. Nucleic Acids Research $\mathbf{3 0}$ $3253-3261$

Saitou N \& Nei M 1987 The neighbor-joining method: a new method for reconstructing phylogenetic trees. Molecular Biology and Evolution 4 406-425.

Sambrook J, Fritsch EF \& Maniatis T 1989 Molecular Cloning: a Laboratory Manual, edn 2, pp. I.43-I.45. Cold Spring Harbor, New York: Cold Spring Harbor Press.

Schmid CW 1998 Does SINE evolution preclude Alu function? Nucleic Acids Research 26 4541-4550.

Schoner W 2002 Endogenous cardiac glycosides, a new class of steroid hormones. European Fournal of Biochemistry 269 2440-2448.

Smutzer G \& Chamberlin LL 1998 The translational start sites of jawless and cartilaginous fish genes. Molecular Marine Biology and Biotechnology 7 303-311.

Stocco DM 2001 StAR protein and the regulation of steroid hormone biosynthesis. Annual Review of Physiology 63 193-213.
Stocco DM 2002 Clinical disorders associated with abnormal cholesterol transport: mutations in the steroidogenic acute regulatory protein. Molecular and Cellular Endocrinology 191 19-25.

Stocco DM \& Clark BJ 1996 Role of the steroidogenic acute regulatory protein (StAR) in steroidogenesis. Biochemical Pharmacology 51 197-205.

Strauss JF 3rd, Kishida T, Christenson LK, Fujimoto T \& Hiroi H 2003 START domain proteins and the intracellular trafficking of cholesterol in steroidogenic cells. Molecular and Cellular Endocrinology $20259-65$.

Sugawara T, Lin D, Holt JA, Martin KO, Javitt NB, Miller WL \& Strauss JF 3rd 1995a Structure of the human steroidogenic acute regulatory protein (StAR) gene: StAR stimulates mitochondrial cholesterol 27-hydroxylase activity. Biochemistry 34 12506-12512.

Sugawara T, Holt JA, Driscoll D, Strauss JF 3rd, Lin D, Miller WL, Patterson D, Clancy KP, Hart IM, Clark BJ et al. 1995b Human steroidogenic acute regulatory protein: functional activity in COS-1 cells, tissue-specific expression, and mapping of the structural gene to $8 \mathrm{p} 11 \cdot 2$ and a pseudogene to chromosome 13 . PNAS 92 4778-4782.

Thompson JD, Higgins DG \& Gibson TJ 1994 CLUSTAL W: improving the sensitivity of progressive multiple sequence alignment through sequence weighting, position-specific gap penalties and weight matrix choice. Nucleic Acids Research 22 4673-4680.

Thorson TB 1970 Freshwater stingrays, Potamotrygon spp.: failure to concentrate urea when exposed to saline medium. Life Sciences II 9 893-900.

Thorson TB, Cowan CM \& Watson DE 1967 Potamotrygon spp.: elasmobranchs with low urea content. Science 158 375-377.

Thorson TB, Wotton RM \& Georgi TA 1978 Rectal gland of freshwater stingrays, Potamotrygon Spp (ChondrichthyesPotamotrygonidae). Biological Bulletin 154 508-516.

Tsujishita Y \& Hurley JH 2000 Structure and lipid transport mechanism of a StAR-related domain. Nature Structural Biology 7 408-414.

von Hofsten J, Karlsson J, Jones I \& Olsson PE 2002 Expression and regulation of fushi tarazu factor-1 and steroidogenic genes during reproduction in Arctic char (Salvelinus alpinus). Biology of Reproduction 67 1297-1304.

Watari H, Arakane F, Moog-Lutz C, Kallen CB, Tomasetto C, Gerton GL, Rio MC, Baker ME \& Strauss JF 3rd 1997 MLN64 contains a domain with homology to the steroidogenic acute regulatory protein (StAR) that stimulates steroidogenesis. PNAS 94 8462-8467.

West LA, Horvat RD, Roess DA, Barisas BG, Juengel JL \& Niswender GD 2001 Steroidogenic acute regulatory protein and peripheral-type benzodiazepine receptor associate at the mitochondrial membrane. Endocrinology 142 502-505.

White PC 2003 Aldosterone: direct effects on and production by the heart. Fournal of Clinical Endocrinology and Metabolism 88 2376-2383.

Wood CM, Matsuo AY, Gonzalez RJ, Wilson RW, Patrick ML \& Val AL 2002 Mechanisms of ion transport in Potamotrygon, a stenohaline freshwater elasmobranch native to the ion-poor blackwaters of the Rio Negro. Fournal of Experimental Biology 205 3039-3054.

Wood CM, Matsuo AY, Wilson RW, Gonzalez RJ, Patrick ML, Playle RC \& Luis Val A 2003 Protection by natural blackwater against disturbances in ion fluxes caused by low $\mathrm{pH}$ exposure in freshwater stingrays endemic to the Rio Negro. Physiological and Biochemical Zoology 76 12-27.

Received 14 September 2005

Accepted 23 September 2005 